\title{
Pteridine-2,4-diamine derivatives as radical scavengers and inhibitors of lipoxygenase that can possess anti-inflammatory properties
}

\begin{abstract}
Background: Reactive oxygen species are associated with inflammation implicated in cancer, atherosclerosis and autoimmune diseases. The complex nature of inflammation and of oxidative stress suggests that dual-target agents may be effective in combating diseases involving reactive oxygen species. Results: A novel series of $\mathrm{N}$-substituted 2,4-diaminopteridines has been synthesized and evaluated as antioxidants in several assays. Many exhibited potent lipid antioxidant properties, and some are inhibitors of soybean lipoxygenase, $\mathrm{IC}_{50}$ values extending down to $100 \mathrm{nM}$ for both targets. Several pteridine derivatives showed efficacy at $0.01 \mathrm{mmol} / \mathrm{kg}$ with little tissue damage in a rat model of colitis. 2-(4-methylpiperazin-1-yl)- $N$-(thiophen-2-ylmethyl)pteridin-4amine (18f) at $0.01 \mathrm{mmol} / \mathrm{kg}$ exhibited potent anti-inflammatory activity (reduction by $41 \%$ ). Conclusion: The 2,4-diaminopteridine core represents a new scaffold for lipoxygenase inhibition as well as sustaining anti-inflammatory properties.
\end{abstract}

Oxidative stress is closely associated with chronic inflammation and plays a crucial role in cancer [1], dyslipidemia [2], atherosclerosis [3] and autoimmune diseases such as systemic lupus erythematosus and rheumatoid arthritis [4]. In many diseases, the rate of production of reactive oxygen species (ROS) is increased compared with normal levels of ROS [5,6]. ROS are produced during the inflammatory process by phagocytic leukocytes that invade the tissue. Under conditions of oxidative stress, ROS including superoxide anion, hydroxyl radical and hydrogen peroxide and their reactive products can attack various biological macromolecules (e.g., proteins, enzymes, DNA and lipids) resulting in DNA mutations, lipid peroxidation and protein oxidation, [7] or they may indirectly interfere with mechanisms of DNA repair [8]. Thus, ROS activity consists of a mixture of deleterious and beneficial roles, depending on the type, concentration and location of the species involved. The breadth of those factors suggests that focused targeting of ROS, probably in a dualtarget or multiple-target approach, could be of therapeutic value.
Reactive oxygen species are centrally involved in the cyclooxygenase (COX)- and lipoxygenase (LOX)-mediated conversion of arachidonic acid (AA) into proinflammatory intermediates $[9,10]$. LOX exerts its biological role via a carbon-centered radical mechanism. LOX metabolism results in many bioregulatory molecules such as leukotrienes, lipoxins and hepoxylins, mediators in the pathophysiology of variety of diseases such as rheumatoid arthritis, bronchial asthma, psoriasis, cancer and other inflammatory diseases [11].

In the search for new antioxidants and anti-inflammatory agents, the pteridine ring (Figure 1) was selected for study for several reasons: many naturally-occurring derivatives possess important biological activity, including the coenzymes 5,6,7,8-tetrahydrobiopterin and the pterins; the ring system has low toxicity; synthetic pteridine derivatives show a wide range of clinically useful properties, for example, as antioxidants, immunosuppressants, and anti-inflammatory and anticancer agents. Consequently, multitarget properties were deemed likely, as were the discovery of new agents for a range of dis-
Eleni Pontiki $i^{1,2}$, Dimitra Hadjipavlou-Litina², Alexandros Patsilinakos ${ }^{3}$, Trang M Tran ${ }^{1}$ \& Charles M Marson*,1

${ }^{1}$ Christopher Ingold Laboratories, Department of Chemistry, University College London, 20 Gordon Street, London WC1H OAJ, UK ${ }^{2}$ Department of Pharmaceutical Chemistry, Faculty of Health Sciences, School of Pharmacy, Aristotle University of Thessaloniki, Thessaloniki, 54124, Greece

${ }^{3}$ Rome Center for Molecular Design, Dipartimento di Chimica e Tecnologie del Farmaco, Sapienza University of Rome, 00185 Rome, Italy

*Author for correspondence: Fax: +44 (0)20 76797463 c.m.marson@ucl.ac.uk 


\section{Key terms}

Oxidative stress: Cellular damage resulting from the action of reactive oxygen species on biological molecules in which detoxification of the reactive intermediates and/or molecular repair is insufficient.

Inflammation: Pattern of biological responses arising in attempts to overcome challenges by harmful stimuli, including damaged cells, irritants or pathogens.

Reactive oxygen species: Chemically reactive oxygen species such as anions, radical anions, radicals and peroxides formed as by-products of metabolism.

Lipoxygenases: Iron-containing redox enzymes that catalyze the oxygenation of fatty acids, lipoproteins and other molecules.

Pteridines: Bicyclic heteroaromatic compounds comprising pyrazino $[2,3-d]$ pyrimidine ring fusion.

eases, and also the use of pteridine derivatives to probe the putative targets of diseases.

Substituted pteridines are known to act upon a wide range of targets of therapeutic potential. Thus, a 6,7-disubstituted-2,4-diaminopteridine is a PI3 kinase inhibitor with potential for treatment of myocardial infarction involving ischemia reperfusion injury [12]. 2-Amino-4-piperazin-1-yl-6-(3,4-dimethoxyphenyl)pteridines have been shown to possess immunosuppressive and anti-inflammatory properties [13], and analogues of the potent phosphodiesterase- 4 inhibitor 7-benzylamino-6-chloro-2-piperazin-1-yl4-pyrrolidin-1-ylpteridine which inhibits growth in tumor cell lines required a 2-piperazin-1-yl substituent for optimal potency [14]. Some 2-amino-4-(N,Ndiarylmethyl)-6-arylpteridines inhibit neuronal nitric oxide synthase [15] and some 2,4-diamino-4,6-dia- rylpteridines inhibit inducible or inflammatory nitric oxide synthase [16]. Several 2,4-diamino-6-arylaminomethylpteridines are potent inhibitors of parasitic pteridine reductases, and have promising antiparasitic potential $[17,18]$. Adequate dietary content of folic acid (pteroyl L-glutamic acid; Figure 1) is a requirement for human health and on which DNA synthesis, DNA repair and DNA methylation depend [19].

In addition to the treatment of a variety of cancers, the antifolate methotrexate reduces inflammation in the bowel and is used for treating Crohn's disease, ulcerative colitis, rheumatoid arthritis, psoriasis and other autoimmune diseases. Therefore, novel compounds bearing the pteridine ring could exhibit antiinflammatory and antioxidant activities and have potential as therapy for a wide range of diseases involving inflammation. The 2,4-diaminopteridine core of methotrexate (Figure 1), was used as the scaffold in this study. Alkylamino and dialkylamino substituted 2,4-diaminopteridines were investigated since many have a range of drug-like clogP values (1.0-4.0, Table 1) and because synthesis should afford the required structural diversity. We describe here the synthesis and preliminary evaluation of some novel $N$-alkylated 2,4-diaminopteridine derivatives as dual-target agents through their radical scavenging properties, inhibition of lipoxygenase and in vivo anti-inflammatory activity.

\section{Results \& discussion Chemistry}

Routes to 2,4-diaminopteridine derivatives with no substituents at the 6- or 7-postions are sparse. In particular, very few such compounds contain a tertiary amine at the 2-position (Figure 2). Two relevant<smiles>C[C@@H](O)[C@H](O)[C@H]1CNc2[nH]c(N)nc(=O)c2N1</smiles>

Tetrahydrobiopterin<smiles>Nc1nc(=O)c2nc(CNc3ccc(C(=O)N[C@@H](CCC(=O)O)C(=O)O)cc3)cnc2[nH]1</smiles>

Folic acid<smiles></smiles><smiles></smiles>

Figure 1. Pterin and pteridine derivatives of biological or medicinal importance. 


\section{Table 1. Inhibition of soybean lipoxygenase by substituted pteridines.}

\begin{tabular}{|c|c|c|c|c|}
\hline Entry & Compound & Structure & $\operatorname{cLog} \mathrm{P}^{43}$ & $\begin{array}{l}\text { Lipoxygenase inhibitory activity } \\
\left(\mathrm{IC}_{50}[\mu \mathrm{M}] \text { or } \% \text { at } 100 \mu \mathrm{M}\right)\end{array}$ \\
\hline 1 & $5 a$ & & 0.14 & $37.5 \pm 0.1 \%$ \\
\hline 2 & $5 b$ & & 1.08 & $100 \pm 0.3$ \\
\hline 3 & $5 c$ & & 3.73 & $22.5 \pm 0.1 \%$ \\
\hline 4 & 9 & & 0.75 & $5.0 \pm 0.1$ \\
\hline 5 & $10 a$ & & 3.25 & $5.0 \pm 0.1$ \\
\hline 6 & $10 b$ & & 3.99 & $55 \pm 0.2$ \\
\hline 7 & 13 & & -0.16 & $60 \pm 0.3$ \\
\hline
\end{tabular}




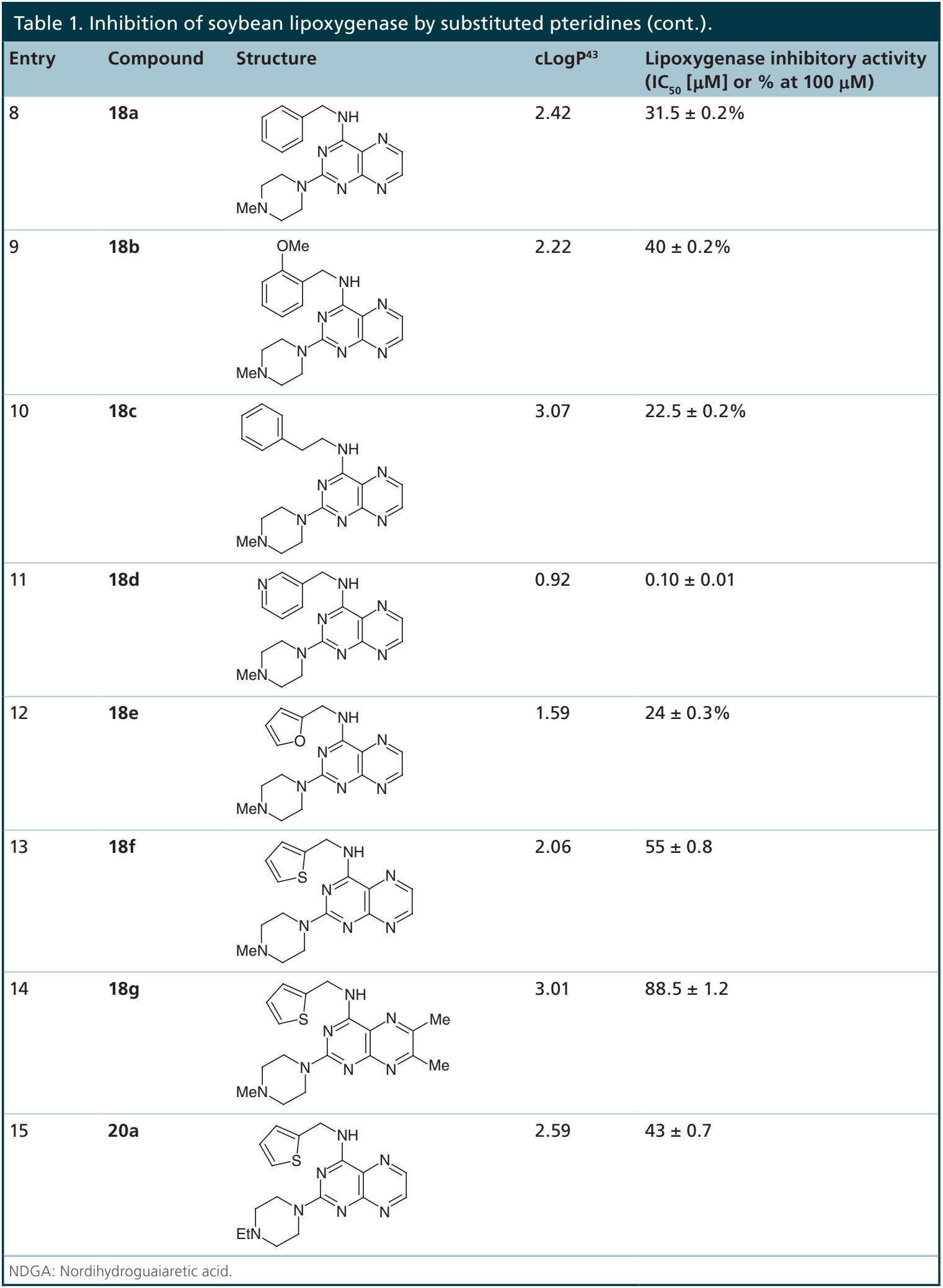


Table 1. Inhibition of soybean lipoxygenase by substituted pteridines (cont.).

\begin{tabular}{|c|c|c|c|c|}
\hline Entry & Compound & Structure & cLog $\mathrm{P}^{43}$ & $\begin{array}{l}\text { Lipoxygenase inhibitory activity } \\
\left(\mathrm{IC}_{50}[\mu \mathrm{M}] \text { or } \% \text { at } 100 \mu \mathrm{M}\right)\end{array}$ \\
\hline 16 & $20 b$ & & 2.05 & $62.5 \pm 0.5$ \\
\hline 17 & 22 & & 1.88 & $80 \pm 2.1$ \\
\hline 18 & 23 & & 3.57 & $19.5 \pm 0.1 \%$ \\
\hline 19 & 24 & & 3.77 & $74 \pm 3.5$ \\
\hline 20 & NDGA & $\mathrm{HO}$ & 3.92 & $1.08 \pm 0.34^{40}$ \\
\hline
\end{tabular}

6,7-disubstituted pteridines had been prepared by reaction of 4-amino-2-methylthio-6,7-diphenylpteridine with morpholine and with piperidine to give the corresponding 2-substituted 4-amino-6,7-diphenylpteridines, but a large excess of the amine was used as the solvent, and it was not known whether this route would permit the introduction of amines other than amino at the 4-position, since only 4,5-diamino-2-methylthiopyrimidine has been used as the early precursor in this route [20]. Accordingly, it was decided to introduce the desired 2,4-diamino substitution prior to the formation of the pteridine ring. Since dimethylamine, pyrrolidine and piperidine had been shown to displace the 2-methylthio group of 4,6-diamino-2-methylthio5-nitrosopyrimidine (3) [21], the route envisaged here involved 5-nitrosation, 2-amination, then reduction and cyclization to give the pteridine ring system (Figure 2).

4,6-diamino-2-thiopyrimidine (1), prepared by condensing thiourea and malononitrile in the presence of sodium ethoxide [22], was $S$-methylated to give 4,6-diamino-2-methylthiopyrimidine (2) by heating with ethanolic methyl iodide at reflux [20]. In a modifi- cation of the literature procedure [23], treatment of $\mathbf{2}$ in aqueous sodium nitrite containing acetic acid afforded the nitrosopyrimidine 3 (95\%) which with 1-methylpiperazine in ethanol at reflux was converted into the 2-(4-methylpiperazin-1-yl)-5-nitrosopyrimidine 4 $(57 \%)$. Reduction of $\mathbf{4}$ with aqueous sodium dithionite afforded the corresponding tetraamine which without isolation was treated with aqueous $40 \%$ glyoxal and then heated at reflux to give 2-(4-methylpiperazin-1-yl) pteridin-4-amine (5a). In the same way, butane-2,3-dione and benzil afforded the corresponding pteridines 5b (68\%) and 5c (59\%).

For 2,4-diaminopteridine derivatives bearing identical 2- and 4-substitution, 6-amino-2,4-dichloropyrimidine was heated at reflux with the appropriate secondary amine to give the triamino-substituted pyrimidines $7(71 \%)$ and 11 (89\%) (Figures 3 \& 4). Using the previous procedure, nitrosation afforded 8 (98\%) and 12 (71\%) which with aqueous sodium dithionite afforded the tetraamines, and again without isolation those were treated with aqueous $40 \%$ glyoxal to afford the corresponding pteridine derivatives 9 (48\%) and 
<smiles>N#CCC(N)=S</smiles><smiles>CS(=O)(=O)c1nc(N)c([N+](=O)[O-])c(N)n1</smiles>

3<smiles>Nc1cc(N)nc(S)n1</smiles>

1
(B)<smiles>CS(=O)(=O)c1nc(N)cc(N)n1</smiles>

2

\section{(C)}

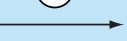<smiles>CN1CCN(c2nc(N)c([N+](=O)[O-])c(N)n2)CC1</smiles><smiles>CCCc1nc2nc(N3CCN(C)CC3)nc(C)c2nc1C</smiles>

$$
\begin{aligned}
& 5 a \mathrm{R}=\mathrm{H} \\
& 5 \mathbf{b} \mathrm{R}=\mathrm{Me} \\
& 5 c \mathrm{R}=\mathrm{Ph}
\end{aligned}
$$

Figure 2. Synthesis of pteridines (5). Reagents and conditions: (A) $\mathrm{Na}$, ethanol, reflux. $2 \mathrm{~h}$; (B) methyl iodide, ethanol, reflux $1.5 \mathrm{~h}$; (C) $\mathrm{NaNO}_{2}$ aqueous acetic acid, $0^{\circ} \mathrm{C}, 2 \mathrm{~h}$ then $4^{\circ} \mathrm{C}, 16 \mathrm{~h}$; (D) 1-methylpiperazine ethanol, reflux $0.75 \mathrm{~h}$ then add water and reflux $0.75 \mathrm{~h}$; (E) sodium dithionite then aqueous $40 \%$ glyoxal (5a) or butane-2,3-dione (5b, or benzil [5c]), reflux $8 \mathrm{~h}, 18 \mathrm{~h}$ and $24 \mathrm{~h}$, respectively.

$13(41 \%)$. The diol 13 was obtained as a mixture of two diastereoisomers that were not separated. Reduction using sodium triacetoxyborohydride (9 mole equivalents) in glacial acetic acid gave the 5-ethyl5,6,7,8-tetrahydropteridine $\mathbf{1 0 a}$ (29\%), after column chromatography. However, when one mole equivalent of triacetoxyborohydride was used, the 5,8-diethyl5,6,7,8-tetrahydropteridine $\mathbf{1 0 b}$ (46\%) was obtained, after column chromatography.
For dissimilar substitution at the 2- and 4-positions of pteridine-2,4-diamine derivatives, a stepwise introduction of those substituents was required. 2,4-dichloropteridine [24] and its derivatives [25] react regioselectively at the 4-position with one equivalent of amine, which makes this approach unsuitable for preparing a range of pteridines with the same 2 -amino substituent. Additionally, the use of 2,4,6,7-tetrachloropteridine for related successive displacements with different amines,<smiles>Nc1cc(Cl)nc(Cl)n1</smiles><smiles>CN1CCN(c2nc(N)cc(N3CCN(S(C)(=O)=O)CC3)n2)CC1</smiles>

(B)<smiles>CN1CCN(c2nc(N)c([N+](=O)[O-])c(N3CCN(C)CC3)n2)CC1</smiles>

8<smiles>CN1CCN(c2nc(N3CCN(S(C)(=O)=O)CC3)c3nccnc3n2)CC1</smiles><smiles>CCNc1nc(N2CCCCC2)nc2c1NCCN2</smiles>

$10 \mathrm{a} \mathrm{R}=\mathrm{H}$

$10 \mathrm{~b} R=\mathrm{Et}$

Figure 3. Synthesis of 5,6,7,8-tetrahydropteridines (10). Reagents and conditions: (A) 1-methylpiperazine, reflux, $18 \mathrm{~h}$; (B) $\mathrm{NaNO}_{2}$ aqueous acetic acid, $0^{\circ} \mathrm{C}, 3 \mathrm{~h}$; (C) sodium dithionite then aqueous $40 \%$ glyoxal, reflux $7 \mathrm{~h}$; (D) $\mathrm{NaHB}(\mathrm{OAC})_{3}$ (9 eq for $10 \mathrm{a}$ and 1 eq for $10 \mathrm{~b}$ ), acetic acid $48 \mathrm{~h}, 20^{\circ} \mathrm{C}$. 


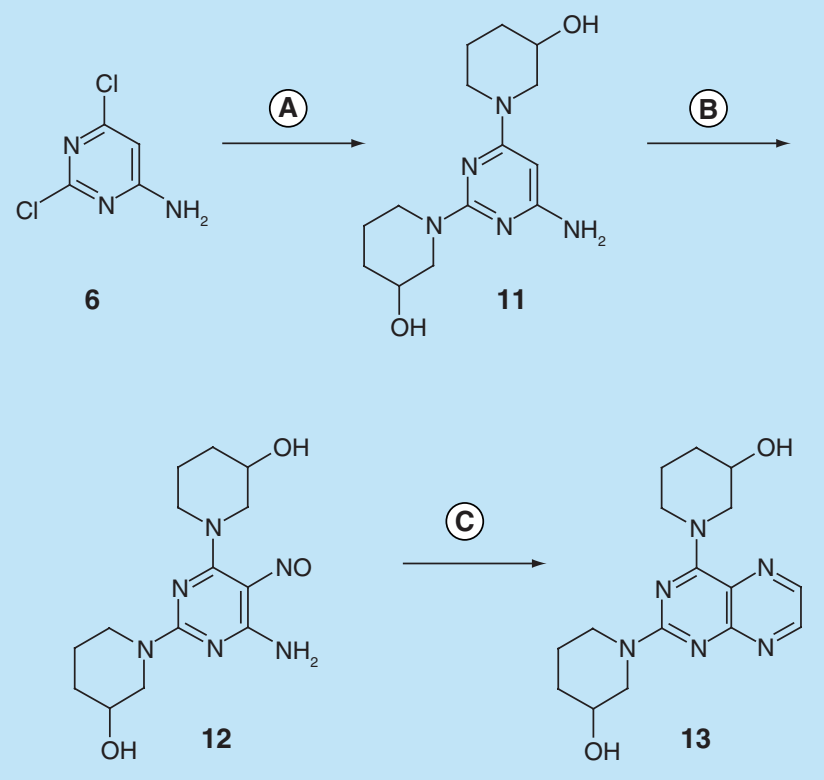

Figure 4. Synthesis of pteridine 13. Reagents and conditions: (A) 3-hydroxypiperazine, reflux 5 h; (B) $\mathrm{NaNO}_{2}$ aqueous acetic acid $0^{\circ} \mathrm{C}, 3 \mathrm{~h}$; (C) sodium dithionite then aqueous $40 \%$ glyoxal, reflux $6 \mathrm{~h}$.

while succinct, afforded extensive mixtures and with isolation of desired single regioisomers usually in low yields, after chromatography [14]. Since the formation of pteridines from 5-nitrosopyrimidines had proved robust and had delivered single regioisomers, this approach was adopted, in which the 4-amino group would be introduced by displacement of 4-amino6-chloro-2-(methylthio)pyrimidine 14 (Figure 5). However, displacement of the chloro group had been reported only for pyrimidine 14, using dimethylamine to install a 4-dimethylamino group [26] . 4,6-Diamino2-methylthiopyrimdines such as $\mathbf{1 5}$ would be required, and would be obtained by displacement of 14 with benzylamine derivatives or with heteroarylmethylamines (Figure 5). Displacement of the 2-methylthio group in 16 by a secondary amine would give the unsymmetrically substituted 2,4,6-triamino-5-nitrosopyrimidines, and hence the corresponding pteridines $\mathbf{1 8 .}$

4-Amino-6-chloro-2-(methylthio) pyrimidine $\mathbf{1 4}$ reacted with a variety of amines (2.1 equivalent) in diglyme at reflux to give the corresponding pyrimidines 15a-f [27] which underwent 5-nitrosation with acidic aqueous sodium nitrite (Figure 5) [23]. The 2-methylthio group of the resulting 5 -nitrosopyrimdines $\mathbf{1 6} \mathbf{a}-\mathbf{f}$ underwent displacement with 1-methylpiperazine or 4-methyl-1,4-diazepane in ethanol at reflux to give the corresponding 2 -amino derivatives $17 \mathbf{a}-\mathbf{f}$. Those were subjected to the above reduction with sodium dithionite followed by condensation with aqueous $40 \%$ glyoxal to give the pteridine derivatives $\mathbf{1 8 a}-\mathbf{g}$. Compounds 20a and 20b were prepared analogously, the latter by using 4-methyl-1,4-diazepane in ethanol at reflux to give 19b. ${ }^{1} \mathrm{H}$ NMR spectra of the nitroso compounds 16, 17 and 19 in chloroform are consistent with the presence of two rotamers arising from hydrogen bonding between the C-5 nitroso oxygen atom and the adjacent $\mathrm{NH}$ hydrogen atoms at $\mathrm{C}-4$, and also with an $\mathrm{NH}$ hydrogen atom at C-6, as established for related pyrimidines [28-30].

A representative 5-nitrosopyrimidine, 17f, was transformed into three 6,5-fused systems (Figure 6) in a brief survey of the relevance of the fused pyrazine ring in the pteridine series. The triazolo[ $4,5-d]$ pyrimidine 21 was obtained by hydrogenation of $\mathbf{1 7 f}$ to the corresponding amine, nitrosation and subsequent ring closure at $90^{\circ} \mathrm{C}$, following standard methods [31]. The 5-nitrosopyrimdine $\mathbf{1 7 f}$ was also converted into $\mathbf{2 2}$ by sodium thiosulfate [32], and into 23 by lead tetraacetate [33]. Synthetic procedures for the new pteridine derivatives are described in detail in the Supplementary Information. All new compounds showed spectroscopic data consistent with the structures proposed. The purity of tested compounds was assessed as at least $95 \%$ by HPLC-MS, unless otherwise indicated.

\section{In vitro lipoxygenase inhibition}

The substituted pteridines prepared were assayed for inhibition of soybean lipoxygenase (Table 1) [34,35] (Supplementary Information). Many studies have used readily obtainable soybean lipoxygenase, which is a homologue of mammalian lipoxygenase and well examined $[36,37]$. The availability of soybean LOX and 


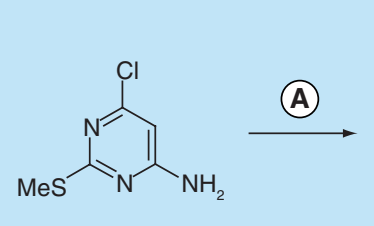

14<smiles>CS(=O)(=O)c1nc(N)cc(NCP)n1</smiles>

$15 a-f$<smiles>[R5]CNc1nc(SC)nc(N)c1[N+](=O)[O-]</smiles>

$16 a-f$<smiles>[R]CNc1nc(N2CCN(C)CC2)nc(N)c1[N+](=O)[O-]</smiles><smiles>[R]CNc1nc(N2CCN(C)CC2)nc2nc([R])c([R])nc12</smiles>

17a $\mathrm{R}^{1}=$ phenyl, $\mathrm{R}^{2}=\mathrm{H}$ 17b $\mathrm{R}^{1}=\mathrm{O}$-anisyl, $\mathrm{R}^{2}=\mathrm{H}$ 17c $R^{1}=$ benzyl, $R^{2}=H$ 17d $\mathrm{R}^{1}=3$-pyridyl, $\mathrm{R}^{2}=\mathrm{H}$ 17e $R^{1}=2$-furyl, $R^{2}=H$ 17f $R^{1}=2$-thienyl, $R^{2}=H$

$$
\begin{aligned}
& 18 a R^{1}=\text { phenyl, } R^{2}=H \\
& 18 b R^{1}=O \text {-anisyl, } R^{2}=H \\
& 18 c R^{1}=\text { benzyl, } R^{2}=H \\
& 18 d R^{1}=3 \text {-pyridyl, } R^{2}=H \\
& 18 e R^{1}=2 \text {-furyl, } R^{2}=H \\
& 18 f R^{1}=2 \text {-thienyl, } R^{2}=H \\
& 18 g R^{1}=2 \text {-thienyl, } R^{2}=M e
\end{aligned}
$$

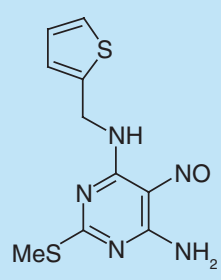

$16 f$

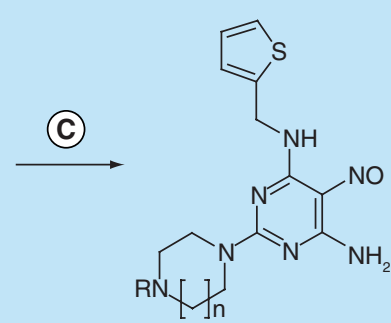

19a $R=E t, n=1$

$19 b \mathrm{~b}=\mathrm{Me}, \mathrm{n}=2$
(D)

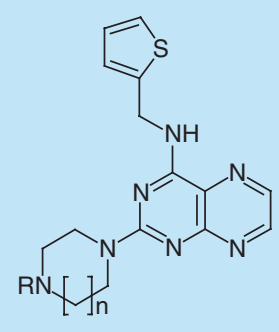

20a $R=E t, n=1$

20b $R=M e, n=2$

Figure 5. Synthesis of pteridines 18 and 20. Reagents and conditions: (A) $\mathrm{R}^{1} \mathrm{CH}_{2} \mathrm{NH}_{2}$ diglyme, reflux, $5 \mathrm{~h}$; (B) $\mathrm{NaNO}_{2}$ aqueous acetic acid, $0^{\circ} \mathrm{C}, 2 \mathrm{~h}$ then $4^{\circ} \mathrm{C}, 16 \mathrm{~h}$; (C) 1-methylpiperazine or 4-methyl-1,4-diazepane, ethanol, reflux, $2 \mathrm{~h}$ then add water and reflux $1 \mathrm{~h}$; (D) sodium dithionite then aqueous $40 \%$ glyoxal or butane-2.3-dione, reflux.

its well-characterized crystal structure [38] led to its use in this study.

In the soybean LOX inhibition assay (Table 1) the three 4-amino-2-(4-methylpiperazin-1-yl)pteridines (entries 1-3) showed only weak inhibition, with increasing bulk of 6,7-substituents not enhancing potency; similarly, the 6,7-dimethyl substitution in compound $\mathbf{1 8 g}$ lowered LOX inhibitory activity, the 6,7-unsubstituted pteridine 18f exhibiting the greater potency. Substitution at the 4-amino group generally increased potency, and within the (hetero)arylmethyl series, polarity in a substituent (18b) or in the appended ring (18d) further increased potency, in the latter case vary greatly. However, the 4-(hetero)arylmethyl series and the 4-(phenethylamine) pteridine 18c showed only moderate potency. Comparison of $18 \mathbf{f}$ with $20 \mathrm{a}$ and $\mathbf{2 0 b}$ shows that both 2-(4-ethylpiperazin-1-yl) and 1-ethyl-1,4-diazepanyl groups conferred lower potency compared with a 2-(4-methylpiperazin-1-yl) moiety. Of the compounds containing a 4-(4-methylpiperazin-1-yl) substituent (entries 4-6), 9 was the most potent pteridine, and $\mathbf{1 0 a}$ the most potent 5,6,7,8-tetrahydropteridine, both having $\mathrm{IC}_{50}=5 \mu \mathrm{M}$ for inhibition of LOX. However, 5,8-diethyl substitution, as in $\mathbf{1 0 b}$, was less well tolerated than the 8 -unsubstituted 10a. A limitation on ring tolerance was also identified; the 3-hydroxypiperidin-1-yl 2,4-disubstitution in $\mathbf{1 3}$ conferred some tenfold less potency than the preferred 2,4-di-(4-methylpiperazin-1-yl) substitution present in 9. The pyrimido[4,5-d]azoles 21-23, containing the standard 2- and 4-substituents, were only moderately potent LOX inhibitors. Lastly, the lipophilicities of the pteridines were considered since a correlation of lipophilicity with LOX inhibition has been reported [39] in other studies but was not detected here [34]. Lipophilicity, as assessed using calculated $\operatorname{cog} \mathrm{P}$ values of the substituted pteridines (Table 1), does not appear to inhibit significantly in vitro LOX, for example, pteridine 9 and the 5,6,7,8-tetrahydropteridine $\mathbf{1 0 a}$ showing equipotent 
inhibition of $\operatorname{LOX}\left(\mathrm{IC}_{50}=5 \mu \mathrm{M}\right)$ although their $\operatorname{clog} \mathrm{P}$ values differ by 2.5 ; however, the most potent LOX inhibitor identified, 18d $\left(\mathrm{IC}_{50}=0.10 \mu \mathrm{M}\right)$, does have a relatively low $\operatorname{cog} \mathrm{P}(0.92)$.

The LOX inhibition data (Table 1) show that the 4-amino substituent plays a crucial role in determining the potency of the substituted pteridine. Thus, although a 4-benzylamino group (entry 8) is almost equipotent to an unsubstituted amino group (entry 5a), a 4-(4-methylpiperazin-1-yl) group (entry 4) shows some tenfold increase in potency. However, a 3-hydroxypiperidin1-yl moiety (entry 7) affords only moderate LOX inhibition. A nitrogen atom in the 4-substituent can confer excellent potency (entry 11). Soybean LOX is able to accommodate the very rigid 4-methylpiperazin-1-yl group present in $9\left(\mathrm{IC}_{50}=5.0 \mu \mathrm{M}\right)$ although the flexible (3-pyridylmethyl)amino group present in $\mathbf{1 8 d}\left(\mathrm{IC}_{50}\right.$ $=0.10 \mu \mathrm{M})$ confers much greater potency. That both substituents are proton acceptors is consistent, in each case, with the distal nitrogen atom engaging in hydrogen bonding. Entries 5 and 8 (Table 1) suggest that in regard to LOX inhibition some steric bulk is tolerated at the 5-position, but is much less well tolerated at the 8-position of the pteridine ring. Although no definite conclusions can currently be drawn, tolerance of some substituents at the 6-and/or 7-positions seems likely.

\section{Molecular modeling of LOX}

Being the most potent inhibitor of soybean LOX of the compounds studied and also possessing efficacy as an antioxidant, pteridine derivative $\mathbf{1 8 d}$ was selected for in silico docking. The molecular modeling study performed (see Supplementary Information for details) provided useful interpretation of the experimental results. The preferred docking orientation for compound $\mathbf{1 8 d}$ is shown in Figure 7. The binding of $\mathbf{1 8 d}$ to soybean LOX (PDB code: 3PZW) has a higher AutoDock Vina score $(-8.5 \mathrm{kcal} / \mathrm{mol})$ than any of the other pteridines docked. Pteridine $\mathbf{1 8 d}$ is able to accommodate the extensively hydrophobic cavity close to the active site, incorporating Ile552, Ile553, Ile538 and Leu546 among other residues. Ile553 and especially Leu 496 are proximate to the hydrophobic 6,7-flank of the pteridine ring, Ile553 also extending to the hydrophobic C4-C6 region of the pyridine ring in 18d. The increased potency of $\mathbf{1 8 d}$ over its phenyl analog $\mathbf{1 8 a}$ is considered to be due to hydrogen binding, perhaps to Ser747. The simplest explanation is that the extension scaffold of $\mathbf{1 8 d}$ into the hydrophobic domain blocks approach of substrates to the active site, and hence prevents oxidation by soybean LOX. The docking simulations of NDGA and $\mathbf{1 8 d}$ show a common pattern of interaction with LOX (Supplementary Figure 1), the terminal rings and central core of each compound showing appreciable overlap. Additionally, Ser747 is engaged in hydrogen bonding with the 3-hydroxyl group of the catechol unit of NDGA, and also with the pyridine nitrogen atom of $\mathbf{1 8 d}$. The relatively weak antioxidant properties of 18d (Table 2) are also consistent with the main mode of action of LOX inhibition being other than by diminish-

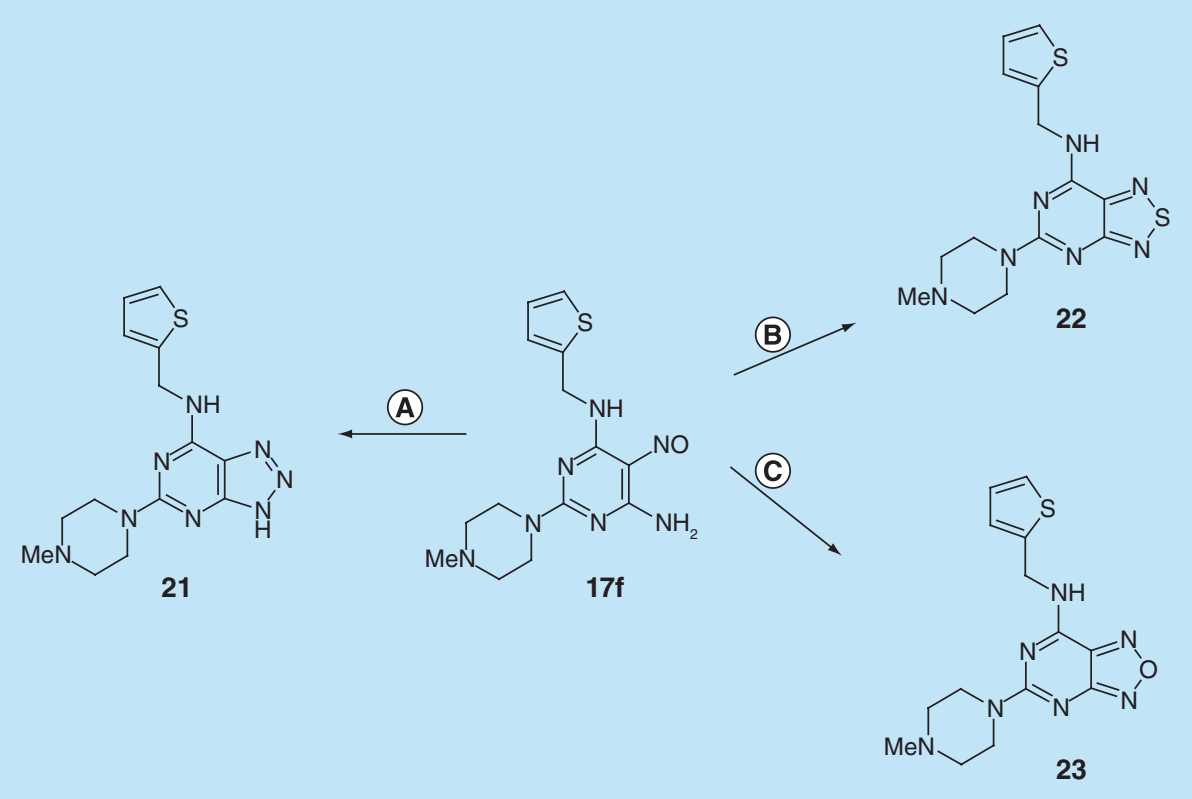

Figure 6. Synthesis of pteridine analogs 21,22 and 23. Reagents and conditions: (A) $\mathrm{H}_{2}, 10 \%$ Pd on C, ethanol; then $\mathrm{NaNO}_{2}$, glacial acetic acid, $90^{\circ} \mathrm{C}, 2 \mathrm{~h}$; (B) sodium thiosulfate pentahydrate, aq. $20 \%$ acetic acid $90^{\circ} \mathrm{C}, 1.5 \mathrm{~h}$; (C) lead tetraacetate, acetic acid, $20^{\circ} \mathrm{C}, 4 \mathrm{~h}$. 


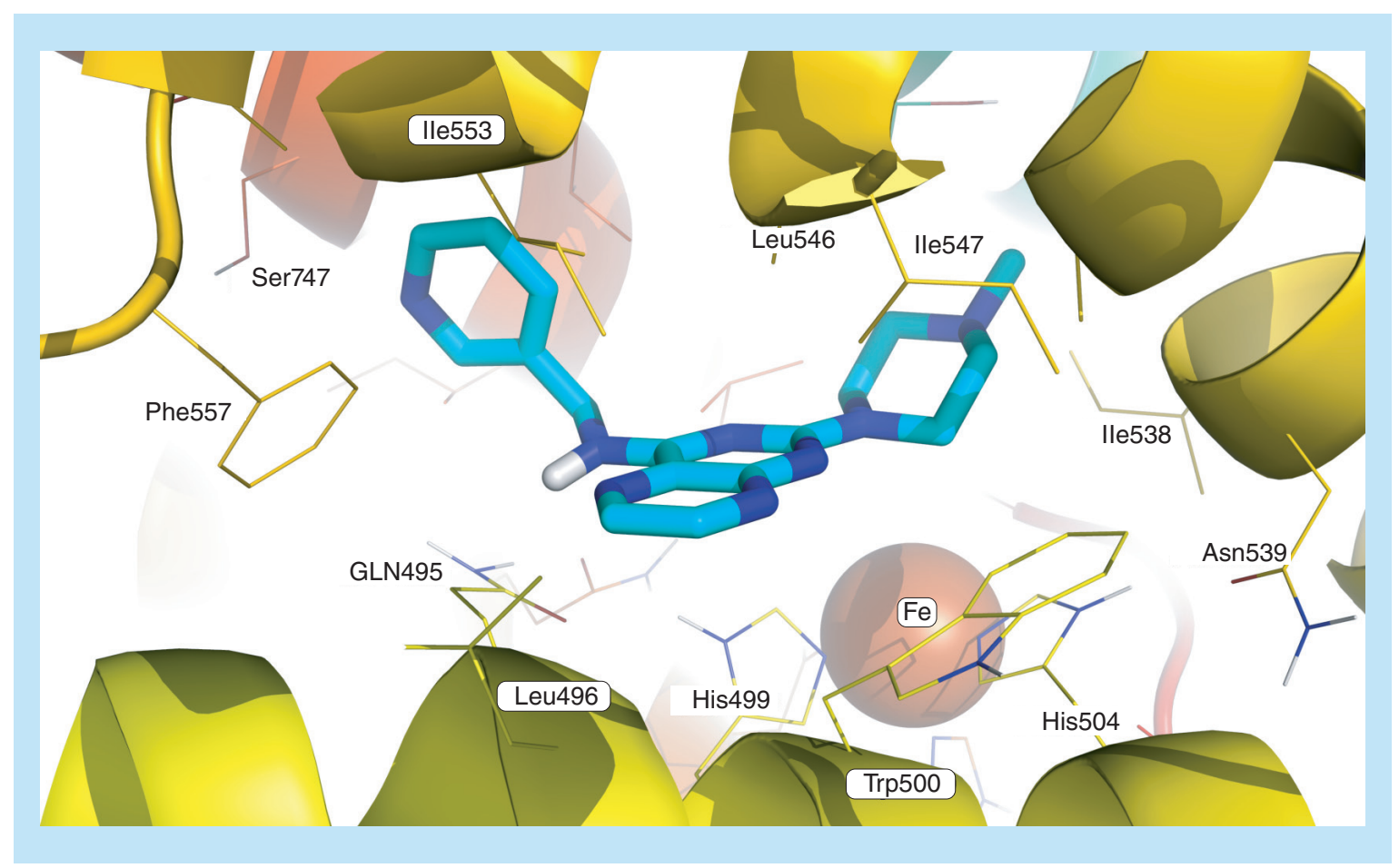

Figure 7. Docking pose of pteridine $18 \mathrm{~d}$ (depicted in turquoise) bound to soybean lipoxygenase (LOX-1) derived by modification of PDB code: 3PZW. Energy minimizations were carried out using the AMBER99SB-ILDN force field [41] with GROMACS as the molecular simulation toolkit [42]. AutoDock Vina (1.1.2) [41] was used for docking. Iron is rendered as a brown sphere. Prepared using PyMOL, this figure represents the preferred pose according to scoring function.

ing general ROS concentrations and hence antioxidant activity [40]. Preliminary screening tests of the pteridines against COX did not present any significant inhibition.

\section{In vitro antioxidant activity}

Previous work has shown that pterins, their dihydro- and their tetrahydro-derivatives can each be antioxidants or pro-oxidants, depending on the particular conditions [43]. In the present study, several assays were used to assess in vitro antioxidant activity in order to obtain representative information; each method involves the generation of a different radical. The three assays chosen measured in vitro antioxidant activity in terms of: reduction of the stable free radical 1,1-diphenyl-2-picrylhydrazyl (DPPH), whose oxidized form possesses an absorption maximum at $517 \mathrm{~nm}$; hydroxyl radical scavenging activity; extent of reduction of the watersoluble 2,2'-azo-bis(2-amidinopropane) dihydrochloride (AAPH) and inhibition of soybean lipoxygenase (Supplementary Information).

The pteridine derivatives were evaluated for their antioxidant activity (Table 2) and compared with that of nordihydroguaiaretic acid (NDGA), the reference compound [39]. Although most compounds at $100 \mu \mathrm{M}$ did not show significant reducing ability, key exceptions were the potent 5-ethyl-5,6,7,8-tetrahydropteri- dine 10a (81\%) and very potent 5,8-diethyl-5,6,7,8tetrahydropteridine 10b (97\%) (Table 2), the latter being more effective than the reference compound.

Competition of the novel pteridine derivatives with dimethyl sulfoxide for hydroxyl radicals was measured. Hydroxyl radicals were generated using the $\mathrm{Fe}^{3+} /$ ascorbic acid system and expressed as a percentage inhibition of formaldehyde production in the presence of each pteridine derivative at $100 \mu \mathrm{M}$ (Table 2) [34]. Pteridine derivatives $5 \mathrm{a}, \mathbf{1 0 b}$ and $\mathbf{1 8 g}$ strongly inhibited the oxidation of dimethyl sulfoxide $(33 \mathrm{mM})$. The majority of the derivatives were excellent scavengers of hydroxyl radicals with activity higher than the reference compound 6-hydroxy-2,5,7,8-tetramethylchroman-2-carboxylic acid (Trolox).

Azo compounds that generate free radicals through spontaneous thermal decomposition are useful for in vitro studies of free radical production. The watersoluble AAPH has been extensively used as a clean and controllable source of thermally produced alkylperoxyl free radicals [44]. In this assay, compound $\mathbf{1 8 g}\left(\mathrm{IC}_{50}=\right.$ $0.1 \mu \mathrm{M}$ ) was the most potent in protecting against lipid peroxidation; next, and almost equipotent, were the pteridines 13 and $\mathbf{1 8 e}$, and the triazolo [4,5-d]pyrimidine 22 and the oxadiazole[3,4- $d]$ pyrimidin-4-amine 24 (each of approximate $\mathrm{IC}_{50}=0.3 \mu \mathrm{M}$ ). The 4 -(thio- 
phen-2-yl)methylamino-substituted pteridine derivatives showed a range of three orders of magnitude, compound $\mathbf{1 8 g}$ showing by far the greatest protection against lipid peroxidation, the 2-(4-ethylpiperazin1-yl) derivative 20a being moderate, the 1,4-diazepane derivative 20b being poor and the 2-(4-methylpiperazin-1-yl) derivative $\mathbf{1 8 f}$ being very weak. Evidently, the presence of 6,7-dimethyl groups on the pteridine ring greatly enhances protection against lipid peroxidation; the nature of the alkyl group and ring size on the 2-substituent has some, but much less, effect. Of the 4-aminopteridines, the 6,7-diphenyl derivative 5c was by far the most potent inhibitor, whereas of the 2,4-bis(4-methylpiperazin-1-yl) derivatives, $\mathbf{1 3}$ is more than twice as potent as the 2,4-(3-hydroxydipiperidin1-yl derivative 9. Reduction of the pteridine ring in compound 9 to the corresponding 5,6,7,8-tetrahydropteridines 10a and 10b decreased protection of lipid peroxidation, with potency decreased by 13 -fold and 20-fold, respectively. Conversely, reduction of the pteridine ring in the 4-(4-methylpiperazin-1-yl) derivative $\mathbf{1 8 f}$ to give $\mathbf{1 8} \mathbf{i}$ increased potency by a factor of about 2.5. In the 6,5-fused heteroaromatic compounds studied, $\mathbf{2 2}$ and $\mathbf{2 4}$ showed similar and potent inhibition of lipid peroxidation whereas compound $\mathbf{2 3}$ was half as potent. The role of lipophilicity (as assessed from calculated $\operatorname{cog} \mathrm{P}$ values; Table 1) is not clear, but substituent bulk plays a significant role.

\section{In vivo anti-inflammatory activity}

LOX has also been associated with inflammation and ulcerative colitis [45]. In the present study, a model for colitis involving intracolonic administration of aqueous $4 \%$ acetic acid in the rat was used, leading to acute inflammatory reaction [46]. Treated rats presented partial to diffuse petechial bleeding, single erosion and limited ulceration indicating an overall healing effect of the compounds. Substituted pteridines presenting a satisfactory combination of activities $\mathbf{5 a}, \mathbf{1 8 a}, \mathbf{1 8 d}$ and $\mathbf{1 8 f}$ were tested using this in vivo model characterized by diffuse exfoliated mucosa as well as multiple and extended erosion and ulcers of the colon (Table 3). No mortality was

\section{Table 2. Reducing ability in 2,2-diphenyl-1-picrylhydrazl assay, scavenging activity of hydroxyl} radicals, and in vitro antilipid peroxidation activity of substituted pteridines.

\begin{tabular}{|c|c|c|c|c|}
\hline \multirow[t]{2}{*}{ Compound } & \multicolumn{2}{|c|}{ RA (\%) $100 \mu \mathrm{M}$} & \multirow{2}{*}{$\begin{array}{l}\text { Hydroxyl radicals } \\
\text { scavenged }(\%)^{\dagger}\end{array}$} & \multirow[t]{2}{*}{ AAPH IC ${ }_{50}(\mu \mathrm{M})$} \\
\hline & $20 \mathrm{~min}$ & $60 \mathrm{~min}$ & & \\
\hline $5 a$ & 15 & 14 & 98 & $41 \pm 1.1$ \\
\hline $5 b$ & 0 & 13 & 94 & $40 \pm 0.8$ \\
\hline $5 c$ & 10 & 6 & 100 & $0.50 \pm 0.03$ \\
\hline 9 & 8 & 14 & 96 & $0.73 \pm 0.2$ \\
\hline $10 a$ & 79 & 81 & 96 & $15 \pm 0.2$ \\
\hline $10 \mathrm{~b}$ & 98 & 97 & 98 & $10 \pm 0.43$ \\
\hline 13 & 6 & 13 & 95 & $0.33 \pm 0.01$ \\
\hline $18 a$ & 2 & 7 & 91 & $22 \pm 0.8$ \\
\hline $18 b$ & 13 & 20 & 90 & $21 \pm 0.9$ \\
\hline $18 c$ & 11 & 18 & 97 & $10 \pm 0.1$ \\
\hline $18 d$ & 10 & 11 & 95 & $32.5 \pm 1.0$ \\
\hline $18 \mathrm{e}$ & 10 & 17 & 94 & $0.33 \pm 0.03$ \\
\hline $18 f$ & 6 & 4 & 96 & $100 \pm 1.5$ \\
\hline $18 \mathrm{~g}$ & 12 & 12 & 100 & $0.10 \pm 0.01$ \\
\hline $20 a$ & 4 & 11 & 92 & $20 \pm 0.5$ \\
\hline $20 b$ & 15 & 19 & 94 & $41 \pm 0.3$ \\
\hline 21 & 4 & 6 & 94 & $0.29 \pm 0.02$ \\
\hline 22 & 7 & 10 & 96 & $0.60 \pm 0.05$ \\
\hline 23 & 16 & 18 & 94 & $0.32 \pm 0.02$ \\
\hline NDGA & 81 & 83 & - & - \\
\hline Trolox & - & - & 73 & 55.5 \\
\hline
\end{tabular}


Table 3. In vivo colitis studies ${ }^{\dagger}$.

\begin{tabular}{|lll|l|}
\hline $\begin{array}{l}\text { Compound } \\
\text { Vehicle (control) }\end{array}$ & $\begin{array}{l}\text { Change in body weight (\%) } \\
\text { Vehicle + acetic acid }\end{array}$ & -6.6 & $\begin{array}{l}\text { Score (levels 0-5) } \\
\text { No activity }\end{array}$ \\
\hline Vehicle + 5a & -1.1 & $\begin{array}{l}\text { Diffuse exfoliated mucosa, multiple erosion and } \\
\text { ulcers (4-5) }\end{array}$ \\
Vehicle + 18a & -4.2 & $\begin{array}{l}\text { One rat presented normal appearance }(0) \text {; the rest } \\
\text { exhibited hyperemia and petechial bleeding (1-2) }\end{array}$ \\
Vehicle + 18d & -7 & $\begin{array}{l}\text { One rat exhibited hyperemia (1); the rest presented } \\
\text { petechial bleeding (patchy to diffuse) (2-3) }\end{array}$ \\
Vehicle + 18f & -10.7 & $\begin{array}{l}\text { One rat exhibited patchy petechial bleeding (2), } \\
\text { and another diffuse petechial bleeding (3); the rest } \\
\text { presented partial exfoliated mucosa or single erosion } \\
\text { or ulcer }\end{array}$ \\
\hline In each case there were two groups, each of three rats. & $\begin{array}{l}\text { All rats exhibited partial to diffuse exfoliated mucosa } \\
\text { or single/multiple erosion or ulceration (4-5) }\end{array}$ \\
\hline
\end{tabular}

encountered. Pteridine 5a (score 1-2) was the most potent in this series, followed by its 4 -( $N$-benzyl) ana$\log , \mathbf{1 8 a}$. Rats treated with $\mathbf{5 a}$ or $\mathbf{1 8 a}$ showed less loss in body weight compared with the control group.

6-chloro-2-(4-methylpiperazin-1-yl)- $N$-(thiophen2-ylmethyl)quinazolin-4-amine possesses in vivo antiinflammatory properties in the rat [47], so on the basis of its close structural analogy with pteridine $\mathbf{1 8 f}$, that latter was tested for anti-inflammatory effects using the carrageenin paw edema model (Table 4). The incipient pattern of this edema is characterized by the effects of histamine and 5-hydroxytryptamine. After $1 \mathrm{~h}$, reduction of edema in the rat paw achieved by the pteridine $\mathbf{1 8 f}$ was appreciably greater than the reduction induced by the reference compound indomethacin, a nonselective COX-inhibitor and commonly used nonsteroidal anti-inflammatory drug. Thus, $\mathbf{1 8 f}$ and some related pteridines offer significant protection against reactive oxygen species produced in a model of colitis, probably on account of their properties as antioxidants and radical scavengers.

\section{Conclusion}

A general synthetic approach to $N, N, N^{\prime}$-trialkylated and $N, N, N^{\prime} N^{\prime}$-tetraalkylated 2,4-diaminopteridines has been described. 2,4-diaminopteridine derivatives have been identified as a new and promising class of radical scavengers, anti-inflammatory agents and inhibitors of

Table 4. Inhibition of carrageenin-induced rat paw edema.

\begin{tabular}{|ll|}
\hline Compound & $\begin{array}{l}\text { Reduction of rat paw edema } \\
\text { after } \mathbf{~} \mathrm{h}(\%)\end{array}$ \\
\hline $18 \mathrm{f}$ & $41^{+}$ \\
\hline Indomethacin & $25^{\dagger}$ \\
\hline \multicolumn{2}{|l}{ Mean of two experiments. } \\
\hline
\end{tabular}

LOX. Potent inhibitors of soybean lipoxygenase include 9, 10a and especially 18d $\left(\mathrm{IC}_{50}=0.1 \mu \mathrm{M}\right)$. To our knowledge, 2,4-aminopteridine is a novel scaffold for LOX inhibitors, although the extent of any LOX isoform selectivity remains to be established. Many of the pteridine derivatives studied displayed potent radical-scavenging activity, especially $5 \mathrm{c}, 9,13,18 \mathrm{e}, 18 \mathrm{~g}, 22$ and $\mathbf{2 4}$, of which $\mathbf{1 8 g}$ is the most potent $\left(\mathrm{IC}_{50}=0.1 \mu \mathrm{M}\right)$ in the linoleic acid peroxidation assay. Several pteridine derivatives showed efficacy at $0.01 \mathrm{mmol} / \mathrm{kg}$ with little tissue damage in a rat model of colitis. 2-(4-methylpiperazin1 -yl) $-N$-(thiophen-2-ylmethyl) pteridin-4-amine (18f) at $0.01 \mathrm{mmol} / \mathrm{kg}$ showed $60 \%$ greater reduction of edema in rat paw than that achieved by the anti-inflammatory agent indomethacin, a nonselective COX-inhibitor. Accordingly, this study demonstrates that some pteridine derivatives have at least a dual-target action. These results prompt a more detailed structural, mechanistic and medicinal investigation of substituted 2,4-diaminopteridines, whose therapeutic potential might lead to new agents for the treatment of inflammatory bowel disease, among other inflammatory diseases.

\section{Future perspective}

Inflammation is a multifactorial phenomenon that is implicated in a wide range of diseases. Enhanced formation of ROS by phagocytic leukocytes during the process of inflammation leads to tissue dysfunction and damage in a number of pathological conditions. ROS oxidize lipids generating peroxides and aldehydes that have pronounced biological effects including damage to DNA and protein, selective alterations in cell signaling and cytotoxicity [42]. Oxidative stress evidently plays a crucial role in those processes.

Given the importance of radical species in inflammation there is an unmet and timely need for new 
radical-scavenging agents. In addition, multiple-target anti-inflammatory agents have potential for the control of a range of diseases including arthritis, cancer and atherosclerosis. The wide-ranging biological activities of pteridine derivatives, including the reduction in reperfusion injury by the 4-amino analog of tetrahydrobiopterin [48], suggest that pteridines may find therapeutic applications in unexplored or little-charted areas. New pteridine derivatives could also be of value as probes of specific biological oxidation.

\section{Supplementary data}

To view the supplementary data that accompany this paper please visit the journal website at: www.future-science.com/ doi/full/10.4155/fmc.15.104

\section{Acknowledgements}

Use of the C-QSAR program (A Leo, Biobyte Corp., 201 West 4th Str., Suite 204, Claremont, CA 91711, USA) and is acknowledged and D Davies is thanked for helpful discussions.

\section{Financial \& competing interests disclosure}

Financial support from the Onassis Public Benefit Foundation for a postdoctoral fellowship to E Pontiki is gratefully acknowledged. Financial support from Wellcome for a vacation bursary scholarship to TM Tran is also acknowledged. The authors have no other relevant affiliations or financial involvement with any organization or entity with a financial interest in or financial conflict with the subject matter or materials discussed in the manuscript apart from those disclosed.

No writing assistance was utilized in the production of this manuscript.

\section{Ethical conduct of research}

The authors state that they have obtained appropriate institutional review board approval or have followed the principles outlined in the Declaration of Helsinki for all human or animal experimental investigations. In addition, for investigations involving human subjects, informed consent has been obtained from the participants involved.

\section{Open access}

This article is distributed under the terms of the Creative Commons Attribution License 4.0 which permits any use, distribution, and reproduction in any medium, provided the original author(s) and the source are credited. To view a copy of the license, visit http://creativecommons.org/licenses/ by/4.0/

\section{Executive summary}

- Reactive oxygen species are associated with inflammation implicated in cancer, atherosclerosis and autoimmune diseases. The pteridine ring, suitably substituted, offers a diverse array of biological activity with potential for the treatment of those diseases.

- New $N$-alkylated 2,4-diaminopteridines were prepared in good chemical yields and possess drug-like properties.

- $\mathrm{N}$-alkylated 2,4-diaminopteridines were shown to possess a range of antioxidant properties and to be inhibitors of lipoxygenase, depending on their $N$-substitution.

- $N$-alkylated 2,4-diaminopteridines are dual-target agents, and can be radical scavengers and inhibitors of lipoxygenase. Some also exhibited potent anti-inflammatory properties, either in an in vivo model of colitis or in a model of odema.

\section{References}

Papers of special note have been highlighted as:

- of interest; $\bullet$ of considerable interest

1 Glasauer A, Chandel NS. Targeting antioxidants for cancer therapy. Biochem. Pharmacol. 92(1), 90-101 (2014).

2 Ku IA, Imboden JB, Hsue PY, Ganz P. Rheumatoid arthritis: model of systemic inflammation driving atherosclerosis. Circ. J. 73(6), 977-985 (2009).

3 Rho YH, Chung CP, Oeser A et al. Interaction between oxidative stress and high-density lipoprotein cholesterol is associated with severity of coronary artery calcification in rheumatoid arthritis. Arthritis Care Res. (Hoboken) 62(10), 1473-1480 (2010).

4 Khan F, Siddiqui AA. Prevalence of anti-3-nitrotyrosine antibodies in the joint synovial fluid of patients with rheumatoid arthritis, osteoarthritis and systemic lupus erythematosus. Clin. Chim. Acta 370 (1-2), 100-107 (2006).

5 Uttara B, Singh AV, Zamboni P, Mahajan RT. Oxidative stress and neurodegenerative diseases: a review of upstream and downstream antioxidant therapeutic options. Curr. Neuropharmacol. 7(1), 65-74 (2009).

6 Waris G, Ahsan H. Reactive oxygen species: role in the development of cancer and various chronic conditions. J. Carcinog. 5, 14 (2006).

7 Lambeth JD, Krause KH, Clark RA. NOX enzymes as novel targets for drug development. Semin. Immunopathol. 30(3), 339-363 (2008).

8 Vera-Ramirez L, Sanchez-Rovira P, Ramirez-Tortosa MC et al. Free radicals in breast carcinogenesis, breast cancer progression and cancer stem cells. Biological bases to develop oxidative-based therapies. Crit. Rev. Oncol. Hematol. 80(3), 347-368 (2011).

9 Garrido G, González D, Delporte C et al. Analgesic and anti-inflammatory effects of Mangifera indica L. extract (Vimang). Phytother. Res. 15(1), 18-21 (2001).

10 Weber V, Rubat C, Duroux E, Lartigue C, Madesclaire M, Coudert P. New 3-and 4-hydroxyfuranones as anti-oxidants and anti-inflammatory agents. Bioorg. Med. Chem. 13(14), 4552-4564 (2005). 
11 Pontiki E, Hadjipavlou-Litina D. Targeting lipoxygenases (LOs): drug design and discovery. Curr. Enzyme Inhibition 9(2), 89-105 (2013).

- A key overview of the medcinal chemsitry of LOX inhibitors.

12 Palanki MS, Dneprovskaia E, Doukas J et al. Discovery of 3,3'-(2,4-diaminopteridine-6,7-diyl)diphenol as an isozymeselective inhibitor of PI3K for the treatment of ischemia reperfusion injury associated with myocardial infarction. J. Med. Chem. 50 (18), 4279-4294 (2007).

13 De Jonghe $S$, Marchand A, Gao LJ et al. Synthesis and in vitro evaluation of 2-amino-4- $N$-piperazinyl-6-(3,4dimethoxyphenyl)-pteridines as dual immunosuppressive and anti-inflammatory agents. Bioorg. Med. Chem. Lett. 21(1), 145-149 (2011).

- A study of some aminopteridines that also display antiinflammatory properties.

14 Merz KH, Marko D, Regiert T, Reiss G, Frank W, Eisenbrand G. Synthesis of 7-benzylamino-6-chloro-2-piperazino-4pyrrolidinopteridine and novel derivatives free of positional isomers. Potent inhibitors of cAMP-specific phosphodiesterase and of malignant tumor cell growth. J. Med. Chem. 41(24), 4733-4743 (1998).

15 Matter $\mathrm{H}$, Kotsonis $\mathrm{P}$, Klingler $\mathrm{O}$ et al. Structural requirements for inhibition of the neuronal nitric oxide synthase (NOS-I): 3D-QSAR analysis of 4-oxo- and 4-amino-pteridine-based inhibitors. J. Med. Chem. 45(14), 2923-2941 (2002).

16 Ma F, Lü G, Zhou WF, Wang QJ, Zhang YH, Yao QZ. Synthesis and biological evaluation of 2,4-diaminopteridine derivatives as nitric oxide synthase inhibitor. Chinese Chem. Lett. 20(4), 420-422 (2009).

17 Cavazzuti A, Paglietti G, Hunter WN et al. Discovery of potent pteridine reductase inhibitors to guide antiparasite drug development. Proc. Natl Acad. Sci. USA 105(5), 1448-1453 (2008).

18 Corona P, Gibellini F, Cavalli A et al. Structure-based selectivity optimization of piperidine-pteridine derivatives as potent Leishmania pteridine reductase inhibitors. J. Med. Chem. 55(19), 8318-8329 (2012).

19 Langie SAS, Achterfeldt S, Gorniak JP et al. Maternal folate depletion and high-fat feeding from weaning affects DNA methylation and DNA repair in brain of adult offspring. FASEB 27, 3323-3334 (2013).

20 Taylor EC, Cain CK. Pteridines. VII. The synthesis of 2-alkylaminopteridines. J. Am. Chem. Soc. 74(7), 1644-1647 (1952).

- Describes the scope and limitations of the displacement of a 2-methylthio group in pteridines by amines.

21 Cresswell RM, Strauss T. Displacement of the 2 -methylmercapto group in pyrimidines bearing a 5 -nitroso substituent. J. Org. Chem. 28(10), 2563-2564 (1963).

-. A powerful synthetic method by which a variety of 2-amino substituents can be introduced prior to the formation of the pteridine ring.

22 Bendich A, Tinker JF, Brown GB. A synthesis of isoguanine labeled with isotopic nitrogen. J. Am. Chem. Soc. 70(9), 3109-3113 (1948).
23 Baddiley J, Lythgoe B, Mcneil D, Todd AR. Experiments on the synthesis of purine nucleosides. Part I. Model experiments on the synthesis of 9-alkylpurines. J. Chem. Soc. 74, 383-386 (1943).

24 Su Q, Ioannidis S, Chuaqui C et al. Discovery of 1-methyl$1 H$-imidazole derivatives as potent Jak2 inhibitors. J. Med. Chem. 57(1), 144-158 (2014).

25 Daly JW, Christensen BE. The preparation and properties of certain 2- and 4-chloro substituted pteridines. J. Am. Chem. Soc. 78(1), 225-228 (1956).

26 Baker BR, Joseph JP, Schaub RE. Puromycin. Synthetic studies. Synthesis of 6-dimethylaminopurine, an hydrolytic fragment. J. Org. Chem. 19(4), 631-637 (1954).

27 Ward AD, Baker BR. Irreversible enzyme inhibitors. 200. Active-site-directed inhibitors of deoxycytidine kinase. J. Med. Chem. 20(1), 88-92 (1977).

28 Procházková E, Cechová L, Janeba Z, Dracínsky M. A switchable intramolecular hydrogen bond in polysubstituted 5-nitrosopyrimidines. J. Org. Chem. 78(20), 10121-10133 (2013).

29 Zhang F-L, Xu M, Vasella A. A new synthesis of pteridines substituted with branched and linear alkenyl groups at $\mathrm{C}(6)$. The nitroso-ene reaction of 4-(alkenoylamino)-5nitrosopyrimidines. Helv. Chim. Acta 90 (3), 521-534 (2007).

30 Marchal A, Nogueras M, Sánchez A et al. Alkoxy-5nitrosopyrimidines: useful building block for the generation of biologically active compounds. Eur. J. Org. Chem. 2010(20), 3823-3830 (2010).

31 Fu J, Yang Y, Zhang XW, Mao WJ, Zhang ZM, Zhu HL. Discovery of $1 H$-benzo [d] [1,2,3] triazol-1-yl-3,4,5trimethoxybenzoate as a potential antiproliferative agent by inhibiting histone deacetylase. Bioorg. Med. Chem. 18(24), 8457-8462 (2010).

32 Nagamatsu T, Islam R, Ashida N. Facile synthesis and evaluation of antitumor and antiviral activities of $[1,2,5]$ thiadiazolo[3,4- $d]$ pyrimidines (8-thiapurines) and $4-\beta$-D-ribofuranosyl $[1,2,5]$ thiadiazolo $[3,4-d]$ pyrimidines. Heterocycles 72, 573-588 (2007).

33 Boyle PH, Lockhart RJ. Preparation of 5-amino-7 $(6 H)$ furazano[3,4- $d]$ pyrimidinone an analog of pterin. Tetrahedron 40(5), 879-886 (1984).

34 Pontiki E, Hadjipavlou-Litina D, Litinas K, Nicolotti O, Carotti A. Design, synthesis and pharmacobiological evaluation of novel acrylic acid derivatives acting as lipoxygenase and cyclooxygenase-1 inhibitors with antioxidant and anti-inflammatory activities. Eur. J. Med. Chem. 46(1), 191-200 (2011).

- Shows that inhibitors of soybean LOX and of COX-1 can be designed and synthesized; a pertinent example of dual inhibitors involving LOX.

35 Pontiki E, Hadjipavlou-Litina D. Synthesis and pharmacochemical evaluation of novel arylacetic acid inhibitors of lipoxygenase, antioxidants, and anti-inflammatory agents. Bioorg. Med. Chem. 15(17), 5819-5827 (2007).

- Although structurally unrelated to pteridines, some of these inhibitors are also both LOX inhibitors and antiinflammatory agents. 
Minor W, Steczko J, Bolin JT, Otwinowski Z, Axelrod B. Crystallographic determination of the active site iron and its ligands in soybean lipoxygenase L-1. Biochemistry 32(25), 6320-6323 (1993).

37 Skrzypczak-Jankun E, Amzel LM, Kroa BA, Funk MO. Structure of soybean lipoxygenase L3 and a comparison with its L1 isoenzyme. Proteins 29(1), 15-31 (1997).

Chruszcz M, Wlodawer A, Minor W. Determination of protein structures - a series of fortunate events. Biophys. J. 95(1), 1-9 (2008)

39 Pontiki E, Hadjipavlou-Litina D. Antioxidant and antiinflammatory activity of aryl-acetic and hydroxamic acids as novel lipoxygenase inhibitors. Med. Chem. 2(3), 251-264 (2006).

40

Denisov ET, Afanas'ev IB. Oxidation and Antioxidants in Organic Chemistry and Biology. CRC Press, FL, USA (2005).

41 Pettersen EF, Goddard TD, Huang CC et al. UCSF Chimera - a visualization system for exploratory research and analysis. J. Comput. Chem. 25, 1605-1612 (2004).

42 Fiser A, Sali A. Modeller: generation and refinement of homology-based protein structure models. Meth. Enzymol. 374, 461-491 (2003).
43 Oettl K, Reibnegger G. Pteridine derivatives as modulators of oxidative stress. Curr. Drug Metabol. 3(2), 203-209 (2002).

44 Betigeri S, Thakur A, Raghavan K. Use of 2,2'-azobis(2amidinopropane) dihydrochloride as a reagent tool for evaluation of oxidative stability of drugs. Pharm. Res. 22(2), 310-317 (2005).

45 Hassan GS, Soliman GA. Design, synthesis and antiulcerogenic effect of some of furo-salicylic acid derivatives on acetic acid-induced ulcerative colitis. Eur. J. Med. Chem. 45(9), 4104-4112 (2010).

46 Fabia R, Willén R, Ar'rajab A, Andersson R, Ahrén B, Bengmark S. Acetic acid-induced colitis in the rat: a reproducible experimental model for acute ulcerative colitis. Eur. Surg. Res. 24(4), 211-225 (1992).

47 Smits RA, de Esch IJ, Zuiderveld OP et al. Discovery of quinazolines as histamine $\mathrm{H}_{4}$ receptor inverse agonists using a scaffold hopping approach. J. Med. Chem. 51(24), 7855-7865 (2008).

48 Brandacher G, Zou Y, Obrist P, Steurer W, Werner-Felmeyer G, Margreiter R. The 4-amino analogue of tetrahydrobiopterin efficiently prolongs murine cardiac-allograft survival. J. Heart Lung Transplant. 20, 747-749 (2001). 